\title{
CALCULATION METHOD FOR FLOW BOILING AND FLOW CONDENSATION OF R134A AND R1234YF IN CONVENTIONAL AND SMALL DIAMETER CHANNELS
}

\author{
Dariusz Mikielewicz \\ Blanka Jakubowska \\ Gdansk University of Technology, Poland
}

\begin{abstract}
The paper presents the results of calculations performed using the authors' model to predict the heat transfer coefficient during flow boiling for two refrigerants R134a and R1234yf. The experimental data from various past studies have been collected and the calculations have been conducted for the full range of quality variation and a wide range of mass velocity. The aim of the study was to test the sensitivity of the in-house flow boiling and flow condensation model. The importance of taking into account the surface tension as the parameter exhibiting its importance in case of the flow in minichannels, as well as the influence of the reduced pressure were analysed. The obtained numerical results show good consistency with those recorded in the experiments.
\end{abstract}

Keywords: heat transfer coefficient, flow boiling, conventional channels, minichannels

\section{NOMENCLATURE}

$\begin{array}{ll}B & - \text { blowing parameter } \\ \text { Bo } & - \text { boiling number } \\ C & - \text { mass concentration of droplets in two-phase core } \\ \text { Con } & - \text { confinement number } \\ c_{p} & - \text { specific heat, } / \mathrm{kgK} \\ d & - \text { diameter, } \mathrm{m} \\ f_{,} f_{r} & - \text { friction factor } \\ f_{1}, f_{1 z} & - \text { function } \\ G & - \text { mass flux, } \mathrm{kg} / \mathrm{m}^{2} \mathrm{~s} \\ h & - \text { heat transfer coefficient, } \mathrm{W} / \mathrm{m}^{2} \mathrm{~K} \\ M & - \text { molecular weight, } \mathrm{kg} / \mathrm{kmol} \\ \mathrm{Nu} & - \text { Nusselt number } \\ P & - \text { empirical correction } \\ p & - \text { pressure, Pa } \\ \mathrm{Pr} & - \text { Prandtl number } \\ q & - \text { heat flux, W/m }{ }^{2} \\ r & - \text { specific enthalpy of vaporization, } \mathrm{J} / \mathrm{kg} \\ R & - \text { two-phase multiplier } \\ \mathrm{Re} & - \text { Reynolds number } \\ s & - \text { slip ratio } \\ T & - \text { temperature, } \mathrm{K} \\ x & - \text { quality }\end{array}$

\section{GREEK SYMBOLS}

$\alpha \quad-$ heat transfer coefficient, $\mathrm{W} / \mathrm{m}^{2} \mathrm{~K}$

$\sigma \quad-$ surface tension

$\lambda \quad-$ thermal conductivity, $\mathrm{W} / \mathrm{mK}$

$\rho \quad-$ density, $\mathrm{kg} / \mathrm{m}^{3}$

$\mu \quad-$ dynamic viscosity, $\mathrm{Pa} \mathrm{s}$

$\xi=\frac{f_{r}}{4}-$ friction factor

$$
\begin{array}{ll}
\text { SUBSCRIPTS } \\
\begin{array}{ll} 
& \\
\exp & - \text { reference case } \\
F & - \text { experimental } \\
g, v & - \text { vapor } \\
k r & - \text { critical } \\
l & - \text { liquid } \\
L O & - \text { total liquid flow rate } \\
M S & - \text { Müller-Steinhagen and Heck correlation } \\
P b & - \text { pool boiling } \\
r & - \text { reduced } \\
s a t & - \text { saturation } \\
T B P & - \text { two-phase boiling } \\
t h & - \text { theoretical }
\end{array}
\end{array}
$$




\section{INTRODUCTION}

In the light of increasing interest in refrigerants possessing low global warming potential (GWP), new fluids used in airconditioning and refrigeration units cannot be manufactured with fluorinated greenhouse gases having GWP greater than 150 [1]. Since one of the most popular hydrofluorocarbons (HFC), namely refrigerant R134a, has a 100-year GWP equal to 1430 in low to medium evaporation temperatures [2], it needs to be replaced by more environmentally friendly refrigerants. The need for refrigerant replacements for example in marine air conditioning and refrigeration systems is very urgent, and R134a should be substituted by other environmentally friendly refrigerants in the near future. Previous studies have considered R152a [3] and the natural refrigerant $\mathrm{CO}_{2}[4]$ as possible replacements for R134a in marine air conditioning systems. It should be borne in mind, however, that R152a is a flammable refrigerant, while for the $\mathrm{CO}_{2}$ system the working pressure is significantly higher than that for the R134a system, which would lead to significant system modifications and higher costs [5]. Recently, R1234yf has been believed to be a promising candidate as an alternative for R134a [6]. Its ODP is equal to 0 , whereas GWP 4 and thermophysical properties are similar to those of R134a. Hence, it meets quite well recent environmental requirements and policies. The main thermophysical properties of R1234yf and R134a are summarized in Table 1.

Park and Jung [8] have reported that R1234yf and R134a have similar nucleate heat transfer coefficients and similar, low toxicity. R1234yf also has mild flammability, compared to R32 and other hydrocarbon refrigerants [7]. Nevertheless, minimizing the refrigerant charge is still important to further reduce the risk related to the flammability of R1234yf, a promising candidate for successful use in systems currently designed for R134a.

There are many available experimental investigations into flow boiling heat transfer of R134a in the literature. Typical experimental ranges of these studies have been collected in Table 2. Unfortunately, the results published for R1234yf are still limited and inconsistent. For instance, Satioh et al. [11] studied the boiling heat transfer of the refrigerant R1234yf flowing in a smooth small-diameter horizontal tube, the inertial diameter of which was $2 \mathrm{~mm}$. From the low to the high vapor quality region the difference between the heat transfer coefficient of R1234yf and R134a is small [9]. Del Col et al. [10] found that there were no significant differences between the flow boiling performance of R1234yf and R134a. On the other hand, Mortada et al. [26] performed an experiment for $\mathrm{R} 1234 \mathrm{yf}$ and R134a in a $1.1 \mathrm{~mm}$ rectangular channel with mass flux from 20 to $100 \mathrm{~kg} / \mathrm{m}^{2}$ and heat flux varying from 2 to $15 \mathrm{~kW} / \mathrm{m}^{2}$. Their results showed that the heat transfer coefficient for R1234yf is lower by about $40 \%$ than that for R134a $[9,26]$. These results are in opposition to the findings of [10] and [11].
Table 1: Main thermophysical properties of R134a and R1234yf [7].

\begin{tabular}{|l|c|c|}
\hline & R134a & R1234yf \\
\hline Chemical formula & $\mathrm{C}_{2} \mathrm{H}_{2} \mathrm{~F}_{4}$ & $\mathrm{CF}_{3} \mathrm{CF}=\mathrm{CH}_{2}$ \\
\hline Boiling point $\left[{ }^{\circ} \mathrm{C}\right]$ & -26 & -29 \\
\hline Critical point $\left[{ }^{\circ} \mathrm{C}\right]$ & 102 & 95 \\
\hline Molar mass $[\mathrm{kg} / \mathrm{kmol}]$ & 102.03 & 114.04 \\
\hline Liquid density at $25[\mathrm{~kg} / \mathrm{m} 3]$ & 1206.7 & 1091.9 \\
\hline Vapor density at $25[\mathrm{~kg} / \mathrm{m} 3]$ & 32.350 & 37.925 \\
\hline Liquid enthalpy at $25[\mathrm{~kJ} / \mathrm{kg}]$ & 234.55 & 70.076 \\
\hline Vapor enthalpy at $25[\mathrm{~kJ} / \mathrm{kg}]$ & 412.33 & 215.44 \\
\hline Liquid therm. cond. at $25[\mathrm{~kW} / \mathrm{mK}]$ & 81.134 & 63.585 \\
\hline Vapor therm. cond. at $25[\mathrm{~kW} / \mathrm{mK}]$ & 13.825 & 13.966 \\
\hline Liquid Viscosity $[\mu \mathrm{Pa} s]$ & 194.89 & 155.45 \\
\hline Vapor Viscosity $[\mu \mathrm{Pa} s]$ & 11.693 & 12.291 \\
\hline Surface tension $[\mathrm{N} / \mathrm{m}]$ & $808 \times 10^{-5}$ & $616 \times 10^{-5}$ \\
\hline
\end{tabular}

In the literature, there are many empirical correlations for modelling of boiling heat transfer, and in the case of such fluids as R134a and R1234yf they have proved rather good consistency with experimental data. Several publications, namely by Ribatski [27], Tibirçá and Ribatski [28], Sardeshpande and Ranade [29], and Alagesan [30] analyse the experimental data for validation of heat transfer coefficient predictions using correlations available in the literature. In the present paper, the experimental results collected from the literature are compared with the predictions of the model [31,32]. Based on the evidence of comparison with the abovementioned experimental data, a correction making use of the reduced pressure effect has been applied to the authors' model to provide feasibly the best consistency of the predictions with the experiments.

\section{THE MODEL}

The versatile semi-empirical model to calculate flow boiling and flow condensation due to D. Mikielewicz et al. [31,32] has been tested for a significant number of experimental data and has returned satisfactory results for cases of flow boiling processes in numerous fluids. The fundamental hypothesis of the model is the fact that heat transfer during flow boiling with bubble generation can be modelled as a sum of two contributions constituting the total energy dissipation in the flow, namely the energy dissipation due to shearing flow without bubbles and the dissipation resulting from bubble generation. 
Table 2: Range of variation of experimental data for flow boiling of refrigerants R134a and R1234yf, with the corresponding confinement number Con and reduced pressure.

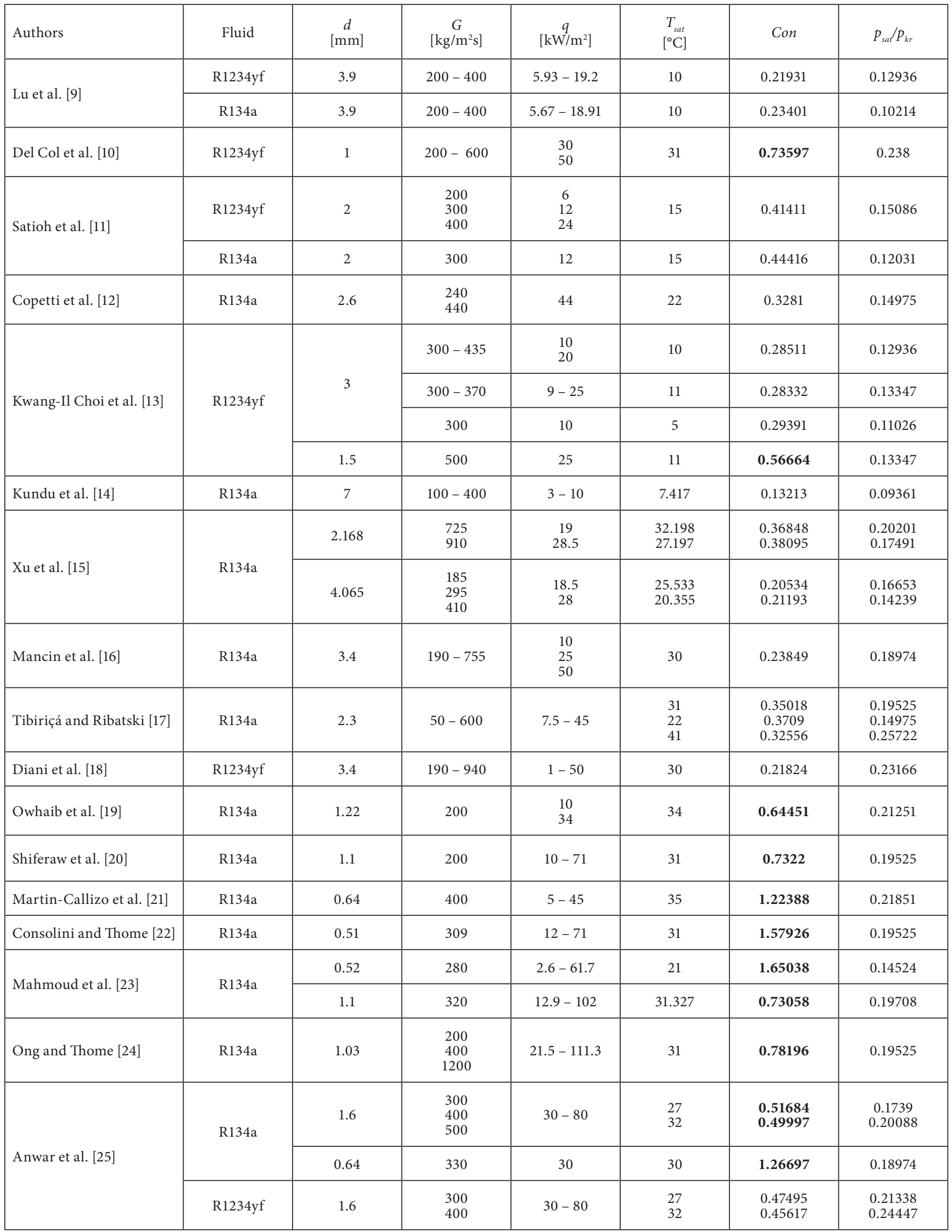


The final version of the model [32] reads:

$$
\frac{\alpha_{T B P}}{\alpha_{L O}}=\sqrt{R_{M S}^{n}+\frac{C}{1+P}\left(\frac{\alpha_{P b}}{\alpha_{L O}}\right)^{2}}
$$

In Equation (1) $\mathrm{C}=1$ for flow boiling and $\mathrm{C}=0$ for flow condensation, whereas $\alpha_{L O}$ is the heat transfer coefficient for the liquid only case. It may be determined using, for example, the Dittus - Boelter equation, (for turbulent flow), or $\mathrm{Nu}=3.66$ (for laminar flow). Equation (1) also includes the empirical correction $P$ and the modified two-phase multiplier, $R_{M S}$, due to Müller - Steinhagen and Heck [33]. The modified form of the two-phase multiplier $R_{M S}$ is:

$$
R_{M S}=\left[1+2 \cdot\left(\frac{1}{f_{1}}-1\right) \cdot x \cdot \operatorname{Con}^{m}\right] \cdot(1-x)^{\frac{1}{3}}+x^{3} \cdot \frac{1}{f_{1 z}}
$$

It should be noted that the two-phase multiplier $R_{M S}$ in Equation (2) is raised to the power $n$, where $n=0.76$ for turbulent flows, and $n=2$ for laminar flows. Function $f_{1}$ in Equation (3) is defined as the ratio of the pressure drop in the single-phase flow of liquid to the pressure drop in the single-phase flow of gas, whereas $f_{1 z}$ denotes the ratio of the single phase-flow heat transfer coefficient in vapour to the single-phase heat transfer coefficient for liquid, respectively. For turbulent flows these functions can be determined from relations: $f_{1}=\left(r_{L} / r_{G}\right)\left(m_{L} / m_{G}\right)^{0.25}, f_{1 z}=\left(m_{G} / m_{L}\right)\left(l_{L} / l_{G}\right)^{1.5}\left(c_{p L} / c_{p G}\right)$, while for laminar flows: $f_{1}=\left(r_{L} / r_{G}\right)\left(m_{L} / m_{G}\right)^{-1}$ and $f_{1 z}=\left(l_{G} / l_{L}\right)$. Furthermore, the exponent $m=0$ for flow in conventional channels, and $m=-1$ for flow in minichannels. The empirical correction $P$ in Equation (1) should be calculated as:

$$
P=2.53 \cdot 10^{-3} \cdot \operatorname{Re}^{1.17} \cdot B o^{0.6} \cdot\left(R_{M S}-1\right)^{-0.65}
$$

The pool-boiling heat transfer coefficient $\alpha_{P b}$ (1) can be calculated using a generalized model due to Cooper [34]. This model describes the heat transfer coefficient in the fluid in terms of the reduced pressure, molecular weight, and applied wall heat flux. The Cooper equation which describes the pool-boiling heat transfer coefficient has the form:

$$
\alpha_{P b}=A \cdot p_{r}^{0.12} \cdot\left(-\log p_{r}\right)^{-0.55} \cdot M^{-0.5} \cdot q^{\frac{2}{3}}
$$

The accuracy of model predictions was expected to be improved by some modifications introduced to the empirical correction $P$. The modified empirical correction $P$ yields:

$$
P=2.53 \cdot 10^{-3} \cdot \mathrm{Re}^{1.17} \cdot B o^{0.6} \cdot\left(R_{M S}^{*}-1\right)^{-0.65} \cdot\left(\frac{p_{s a t}}{p_{k r}}\right)^{a}
$$

$R_{M S}^{*}$ in Equation (5) is the two-phase multiplier, calculated using the original version of Muller-Steinhagen and Heck correlation [33]. In using Equation (2), the exponent is always $m=0$. Exponent $a$ was adjusted to the available data bank for R134a and R1234yf presented in Table 2. Another modification of Equation (1) was the change to the value of the exponent $m$ in Equation (2). The sensitivity of the developed model of two-phase flow multiplier and the nonadiabatic effect were tested in calculations. For that purpose, two models were introduced into Equation (1), namely the Muller - Steinhagen and Heck correlation [33]. Additionally, the calculation procedure includes the so called blowing parameter $B$, which is responsible for evaluation of the nonadiabatic effects appearing due to shear stress modification on the liquid-vapour interface [32].

The modified two-phase multiplier $R_{B}$, inclusive of nonadiabatic effects, has the following form [32]:

$$
R_{B}= \begin{cases}R_{M S} \cdot\left(1-\frac{B}{2}\right) & \text { for } 0.1<x \leq 1 \\ R_{M S} \sqrt{1+\left(\frac{8 \cdot \alpha_{P b} \cdot d_{w}}{\lambda_{l} \cdot \operatorname{Re} \cdot \operatorname{Pr} \cdot \xi_{0} \cdot R_{M S}}\right)^{2}} & \text { for } 0 \leq x \leq 0.1\end{cases}
$$

In Equation (6) the two-phase multiplier should be calculated by using the modified Muller-Steinhagen and Heck correlation, Equation (2). The blowing parameter in Equation (6) is defined as [32]:

$$
B=\frac{2 \cdot q \cdot \frac{\rho_{l}}{\rho_{v}}}{f_{r} \cdot G(s-1) \cdot r}
$$

In Equation (7), $s$ is the slip ratio which can be determined from the Zivi relation [32].

$$
s=\sqrt[3]{\frac{\rho_{l}}{\rho_{v}}}
$$

As a result of application of correction (6), a modified heat transfer model is obtained. This model has been adopted for calculations in the present work:

$$
\frac{\alpha_{T B P}}{\alpha_{L O}}=\sqrt{R_{B}^{n}+\frac{C}{1+2.53 \cdot 10^{-3} \cdot \mathrm{Re}^{1.17} \cdot B o^{0.6} \cdot\left(R_{M S}^{*}-1\right)^{-0.65} \cdot p_{r}^{a}}\left(\frac{\alpha_{P b}}{\alpha_{L O}}\right)^{2}}
$$

In the following part, the basic model and its subsequent modifications, which have been selected for discussion, is analysed with respect to predictions of heat transfer coefficient. The exponent $a$ in the modified two-phase flow multiplier in Equation (5) was adjusted to the available data bank for flow boiling of R134a and R1234yf. 


\section{THE RESULTS}

To distinguish between the conventional channels and minichannels the criterion due to Kew and Cornwell [35] has been used, which is based on the so-called confinement number Con, defined as:

$$
\text { Con }=\frac{1}{d} \sqrt{\frac{\sigma}{d\left(\rho_{I}-\rho_{V}\right)}}
$$

It has been postulated that when the confinement number Con is greater than 0.5 then the flow exhibits the properties of the flow in minichannel, in which the surface tension plays a dominant role. Presented below is a selection of studies which have been considered in the present study.

Based on the Kew and Cornwell [35] criterion, the available data bank was divided into conventional size channels and minichannels. Amongst the collected data, the criterion of minichannels, i.e. Con $>0.5$, is fulfilled only by the research due to De Col et al. [10] and Kwang-Il Choi [13] for R1234yf, while for R134a this criterion is fulfilled by research due to Owhaib et al. [19], Shiferaw et al. [20], Martin-Callizo et al. [21], Consolini and Thome [22], Mahmoud et al. [23], and Anwar et al. [25]. It can therefore be concluded that for both R134a and R1234yf, the transition from conventional size channels to minichannels takes place at a channel diameter smaller than $1.5 \mathrm{~mm}$. The relations of the confinement number Con to the saturation temperature for both refrigerants are presented in Figures 1 and 2. The values of the confinement number Con for the analysed refrigerant, together with the reduced pressure values and the range of variation of experimental parameters, are collated in Table 2. The analysis of the parameters in Table 2 indicates the fact that the experimental research data collected for scrutiny cover a full range of quality variation and a relatively wide range of mass velocity.

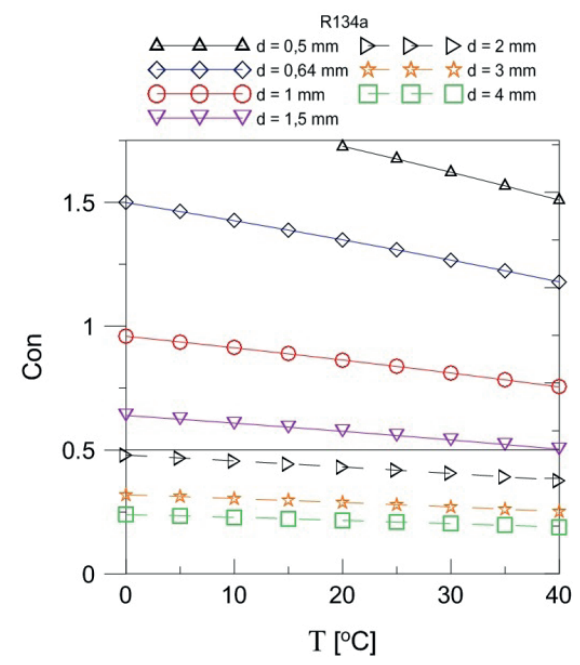

Figure 1: Confinement number Con vs. saturation temperature for R134a

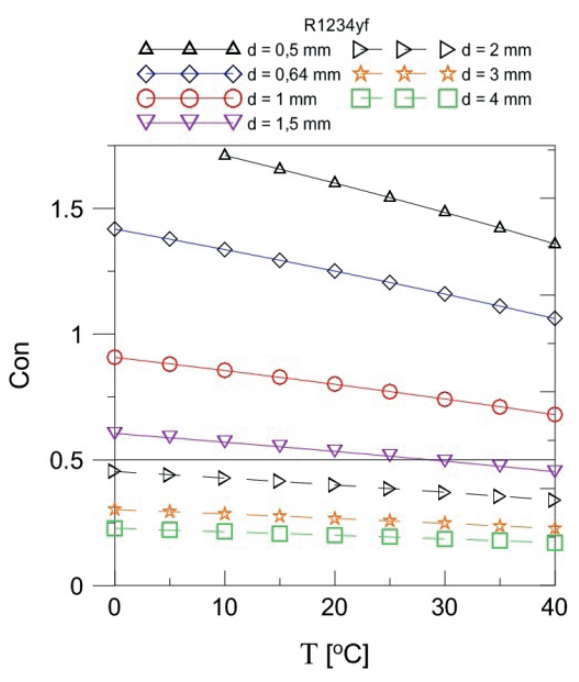

Figure 2: Confinement number Con vs. saturation temperature for R1234yf

Figures 3 to 6 show the results of heat transfer coefficient calculations for R134a and R1234yf by using the earlier mentioned method based on Equation (9). In the adopted formulation, the surface tension effects are included into the analysis by considering the effect of the confinement number in equations through Con. The model version applicable to minichannels was used if Con $>0.5$, and that applicable to convectional size channels when Con $<0.5$. The modification of the empirical correction described by Equation (3) includes the effect of reduced pressure $\left(p_{\text {sat }} / p_{k r}\right)$. The new version of the correction $P$ is applied in Equation (5), where the reduced pressure is raised to the power $a$. The value of the exponent $a$ was adjusted using the regression analysis of functions of several variables. The accomplished calculations indicate that best consistency is obtained if $a=4$ for each case. The information about mean average deviation and correlation factors is given in Table 3. The values of correlation factors are not very high, which indicates relatively high dispersity of the experimental data.

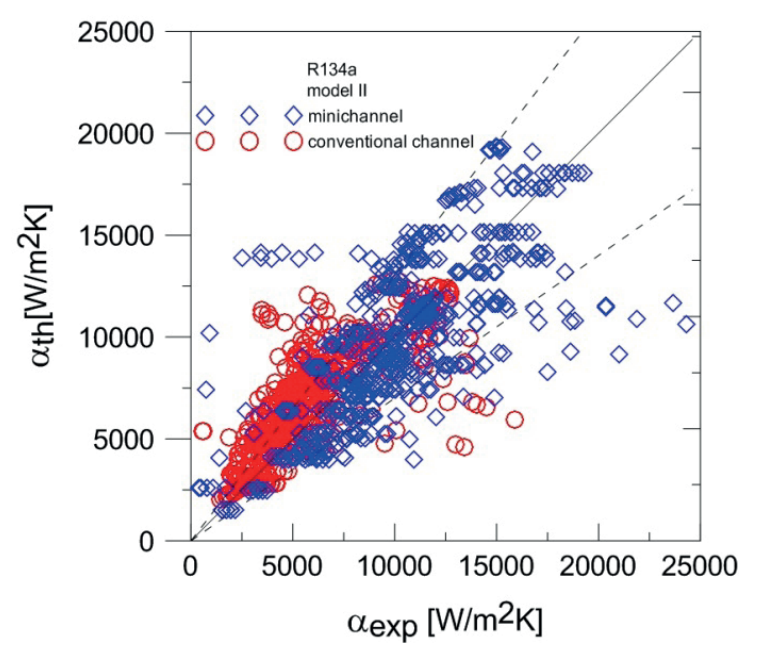

Figure 3: Comparison of test results, $\alpha_{\text {exp }}$ with predictions obtained using Equation (9), $\alpha_{\text {th }}$ and ${ }^{\exp }=4$ for $\mathrm{R} 134 a$ 


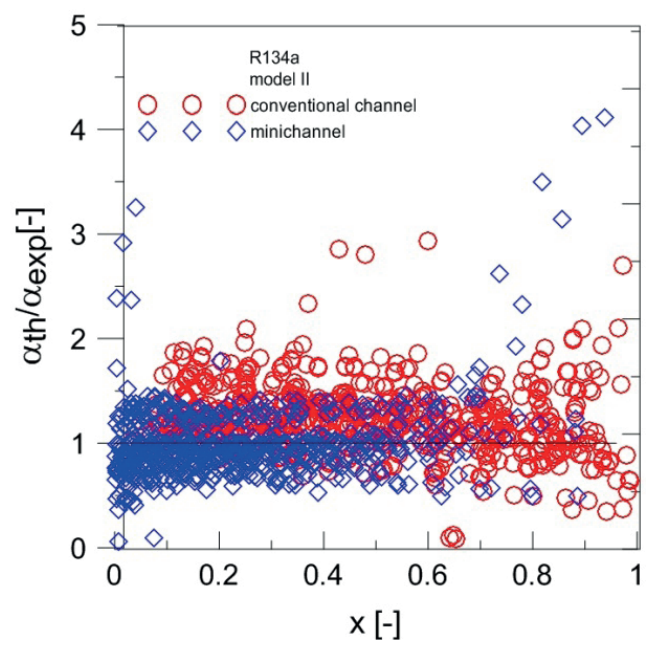

Figure 4: Comparison of the ratio of experimental values of $\alpha_{\text {exp }}$ to those obtained using Equation (9), $\alpha_{\text {th }}$ as function of quality, and $a=4$ for R134a

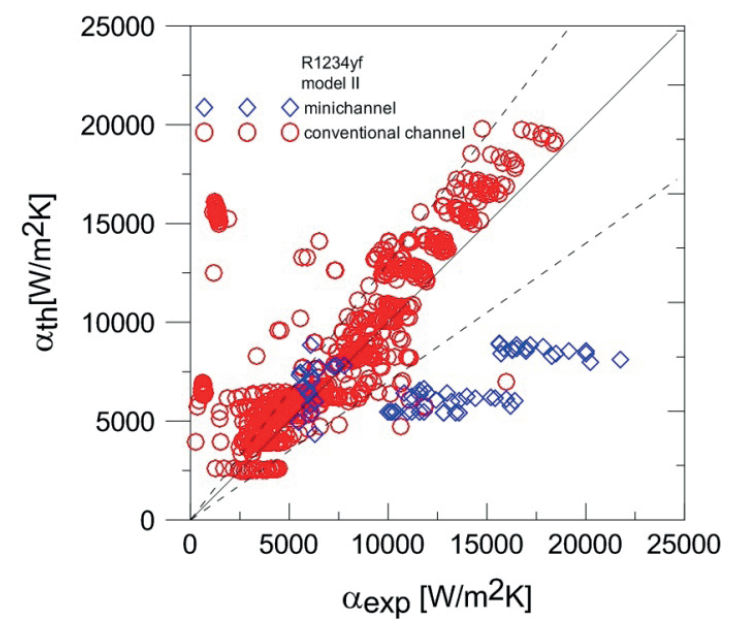

Figure 5: Comparison of test results, $\alpha_{\text {exp }}$ with predictions obtained using Equation (9), $\alpha_{\text {th }}$ and $a=4$ for R1234yf

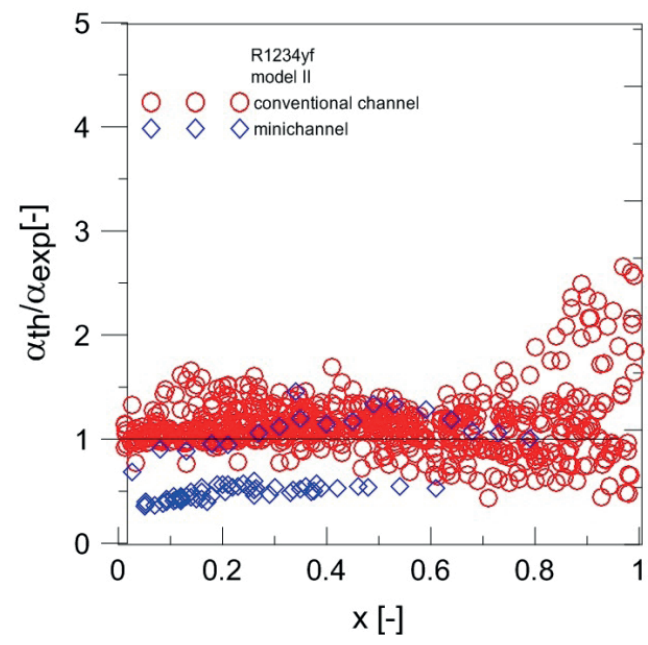

Figure 6: Comparison of the ratio of experimental values of $\alpha$ to those obtained using Equation (9), $\alpha_{\text {th }}$ as function of quality, and $a=4$ for R1234yf
Table 3: Values of exponent $a$ and MAD

\begin{tabular}{|c|c|c|c|}
\hline Fluid & Model & $R^{2}$ & $\begin{array}{c}\text { MAD } \\
{[\%]}\end{array}$ \\
\hline R134a & Model II & 0.1536 & 25.35 \\
\hline R1234yf & Model II & 0.4522 & 16.06 \\
\hline
\end{tabular}

Based on the presented results of calculations, which were obtained using the versions of the heat transfer model described by Equation (9), with and without the account of reduced pressure $\left(p_{s a t} / p_{k r}\right)^{a}$ from Equation (5), it can be concluded that taking into account the effect of reduced pressure improves the convergence with the experimental data, consequently giving smaller values of the mean absolute deviation and higher of the correlation coefficient.

\section{CONCLUSIONS}

The paper presents the analysis of the results of flow boiling and flow condensation calculations using a model developed earlier to study experimental data for flow boiling of R134a and R1234yf. The model was studied in several ways: it was used either in the original formulation or in a modified version, which included the reduced pressure effect in the empirical correction $P$ (value of exponent $a$ was modelled). The results show that the effect of reduced pressure does not significantly change the performance of the original model. The results of calculations show the best compliance with the experimental data when applying the blowing parameter in correlation for each case, i.e. for R134a and R1234yf, and also with and without the account of reduced pressure $\left(p_{\text {sat }}\right.$ / $\left.p_{k r}\right)^{a}$ from Equation (5).

In authors' opinion, the proposed method to calculate the flow boiling heat transfer coefficient is a reliable tool in designing heat exchangers. Among other possibilities, it provides opportunities for analysing other materials which would be more suitable for marine applications, as well as new manufacturing techniques which can be fully automated $[36,37]$. At present, heat exchangers are normally equipped with stainless steel tubes. In future applications, some effort should be made to use plastics [38-40], which do not exhibit susceptibility to corrosion and are cheaper.

\section{REFERENCES}

1. United Nations Environment Program (UNEP) Montreal Protocol on Substances that Deplete the Ozone Layer, 1997.

2. IPPC, Climate Change, Cambridge University Press, Cambridge, United Kingdom, 2001.

3. Ghodbane M.: An investigation of R152a and hydrocarbon refrigerants in mobile air conditioning, Int. Proceedings of International Congress and Exposition, Detroit, Paper no. 1999-01-0874, Warrendale, PA. 
4. Lorentzen G.: Revival of carbon dioxide as refrigerant, Int. J. Refrigeration 17 (3), 1994, pp. 292-301.

5. Zhao Y., Liang Y., Sun Y., Chen J.: Development of a mini-channel evaporator model using R1234yf as working fluid, 35, 2012, pp. 2166-2178.

6. Minor B., Spatz M.: HFO-1234yf low GWP refrigerant update, Int. International Refrigeration and Air Conditioning Conference at Purdue, West Lafayette, IN, USA. Paper no 2349.

7. Refprop v 9.0, National Institute of Standards (NIST), 2010.

8. Park K. J., Jung D.: Nucleate boiling heat transfer coefficients or R1234yf on plain and low fin surfaces, Int. J. Refrigeration 33 (3), 2010, pp. 553-557.

9. Lu M-C., Tong J-R., W C-C.: Investigation of the twophase convective boiling of HFO-1234yf in a $3.9 \mathrm{~mm}$ diameter tube, Int. J. Heat and Mass Transfer, 65, 2013, pp. 545-551.

10. Del Col D., Bortolini S., Torresin D., Cavallini A.: Flow boiling of R1234yf in a $1 \mathrm{~mm}$ diameter channel, Int. J. of Refrigeration, 36, 2013, pp. 353-362.

11. Satioh S., Dang C., Nakamura Y., Hihara E.: Boiling heat transfer of HFO-1234yf flowing in a smooth smalldiameter horizontal tube, Int. J. Refrigeration, 33, 2011, pp. 1846-1853.

12. Copetti J. B., Macaganan M. H., Zinani F.: Experimental study on R-600a boiling in $2.6 \mathrm{~mm}$ tube, Int. J. Refrigeration, 33, 2013, pp. 325-334.

13. Kwang-Il Choi, Jong Taek Oh, Kiyoshi Satio, Jong Soo Jeong: Comparison of Heat Transfer Coefficient during Evaporation of Natural Refrigerants and R-1234yf in Horizontal Small Tube, Int. J. Refrigeration, 2014, 41, pp. $210-218$.

14. Kundu A., Kumar R., Gupta A.: Heat transfer characteristic and flow pattern during two-phase flow boiling of R134a and R407C in a horizontal smooth tube, Experimental Thermal and Fluid Science, 57, 2014, pp. 344-352.

15. Xu Y., Fang X., Li G., Li D.: An experimental study of flow boiling heat transfer of R134a and evaluation of existing correlations, Int. J. Heat and Mass Transfer, 92, 2016, pp. 1143-1157.

16. Mancin S., Diani A., Rossetto L.: R134a flow boiling heat transfer coefficient and pressure drop inside $3.4 \mathrm{~mm}$ ID microfin tube, Energy Proceedia, 45, 2014, pp. 608-615.
17. Tibirçá C. B., Ribatski G.: Flow boiling heat transfer of $\mathrm{R} 134 \mathrm{a}$ and $\mathrm{R} 245 \mathrm{fa}$ in $2.3 \mathrm{~mm}$ tube, Int. J. Heat and Mass Transfer, 53, 2010, pp. 2459-2468.

18. Diani A., Mancin S., Rossetto L.: Flow boiling heat transfer of R1234yf inside $3.4 \mathrm{~mm}$ ID microfin tube, Experimental Thermal and Fluid Science, 66, 2015, pp. 127-136.

19. Owhaib W., Martin-Callizo C., Palm B.: Evaporative heat transfer in vertical circular microchannels, Applied Thermal Engineering, 24, 2004, pp. 1241-1253.

20. Shiferaw D., Karayiannis T. G., Kenning D. B. R.: Flow boiling in a $1.1 \mathrm{~mm}$ tube with R134a: experimental results and comparison with model, Int. J. Thermal Sciences, 48, 2009, pp. 331-341.

21. Martin-Callizo C., Ali R., Palm B.: New experimental results of flow boiling of R134a in vertical microchannel, Heat Transfer Conference Proceedings, Edinburgh 10-11 September, 2007, UK.

22. Consolini L., Thome J. R.: Micro-channel flow boiling heat transfer or R134a, R236fa and R245fa, Microfluid Nanofluids 6, 2009, pp. 731-746.

23. Mahmoud M. M., Kenning D. B. R., Karayiannis T. G.: Single and two phase heat transfer and pressure drop in a $0.52 \mathrm{~mm}$ vertical metallic tube, $7^{\text {th }}$ Int. Conference in Enhanced, Compact and Ultra-compact Heat Exchangers: From Microscale Phenomena to Industrial Applications, September 13-18, Heredia, Costa Rica, 2012.

24. Ong C. I., Thome J. R.: Flow boiling heat transfer of R134a, R236f and R245fa in a horizontal $1.030 \mathrm{~mm}$ circular channel, Exp. Therm. Fluid Sci., 33, 2009, pp. 651-663.

25. Anwar Z., Palm B., Khodabandeh R.: Flow boiling heat transfer, pressure drop and dryout characteristics of R1234yf: Experimental results and predictions, Experimental Thermal and Fluid Science, 66, 2015, pp. 137-149.

26. Mortada S., Zoughaib A., Arzano-Daurelle C., Clodic D.: Boiling heat transfer and pressure drop of HFC-134a and R-1234yf in minichannels for low mass fluxes, Int. J. Refrigeration, 35, 2012, pp. 962-973.

27. Ribatski G.: A critical overview on the recent literature concerning flow boiling and two - phase flows inside microscale channels, ECI $8^{\text {th }}$ Int. Conference on Boiling and Condensation Heat Transfer, 3 - 7 June 2012, Lausanne, Switzerland.

28. Tibirçá C. B., Ribatski G.: Flow boiling in micro-scale channels - Synthesized literature review, Int. J. Refrigeration, 36, 2013, pp. $301-324$. 
29. Sardeshpande M., Ranade V.: Two - phase flow boiling in small channels: A brief review, Sadhana, 38, 2013, pp. 1083 - 1126.

30. Alagesan V.: Flow boiling heat transfer in mini and micro channels - A state of the art review, Int. J. ChemTech Research, 4, 2012, pp. 1247 - 1259.

31. Mikielewicz D., Mikielewicz J., Tesmar J.: Improved semiempirical method for determination of heat transfer coefficient in flow boiling in conventional and small diameter tubes, International Journal of Heat and Mass Transfer, 50(19-20), 2007, pp. 3949-3956.

32. Mikielewicz D., Andrzejczyk R., Jakubowska B., Mikielewicz J.: Analytical model with non-adiabatic effects for pressure drop and heat transfer during boiling and condensation flows in conventional channels and minichannels, Heat Transfer Engineering, 37(13-14), 2016, pp. 1158-1171.

33. Muller-Steinhagen R., Heck K.: A simple friction pressure drop correlation for two-phase flow in pipes, Chem. Eng. Progress, 20, 1986.

34. Cooper M. G.: Saturation nucleate pool boiling; a simple correlation, Int. Chem. Eng. Symposium 1, 86, 1984, pp. $785-793$.

35. Kew P., Cornwell K.: Correlations for the prediction of boiling heat transfer in small diameter channels, Applied Thermal Engineering, 17, 8 - 10, (1997), 705 - 715.

36. Deja M., Siemiątkowski M.S.: Feature-based generation of machining process plans for optimised parts manufacture. Journal of Intelligent Manufacturing, 2013, Vol.24, No.4, pp. 831-846.

37. Szłapczyński R.: Evolutionary Planning of Safe Ship Tracks in Restricted Visibility. Journal of Navigation, 2015, Vol.68, No.1, pp.39-51.

38. Stolarski T.A.: Wear of water-lubricated composite materials. Wear, 1980, Vol.58, No.1, pp. 103-108.

39. Jakubowski M.: Influence of pitting corrosion on fatigue and corrosion fatigue of ship and offshore structures. Part II: Load - pit crack interaction. Polish Maritime Research, 2015, Vol.22, No.3, pp. 57-66.

40. Ambroziak A., Kłosowski P.: Mechanical properties for preliminary design of structures made from PVC coated fabric. Construction and Building Materials, 2014, 50, pp. 74-81.

\section{CONTACT WITH THE AUTHOR}

Dariusz Mikielewicz, e-mail: Dariusz.Mikielewicz@pg.gda.pl,

Gdansk University of Technology, Faculty of Mechanical Engineering, Department of Energy and Industrial Apparatus, ul. Narutowicza 11/12, 80-233 Gdansk Poland

\section{Blanka Jakubowska}

e-mail: blanka.jakubowska@pg.gda.pl

Gdansk University of Technology, Faculty of Mechanical Engineering, Department of Energy and Industrial Apparatus, ul. Narutowicza 11/12, 80-233 Gdansk Poland 